\title{
Colour for time; charting the fourth dimension
}

The pointwise linear regression (PROGRESSOR) technique for visual field analysis and display, described in this issue (p 000) by Viswanathan et al, deserves consideration beyond the comparison of its sensitivity with the STATPAC 2 program. Is it a fashionable solution which has yet to find its problem; yet another technical complexity offered to a medical market often driven by the interest of suppliers such as instrument manufacturers, drug companies, and research workers? Or is it a potentially valuable innovation?

In their introduction the authors summarise the difficulties in detecting significant progressive visual field deterioration. Perhaps no individual digital or mathematical expression can combine all the information required and for many clinicians visual inspection of a graphical display is still the easiest method of rapid and reliable interpretation. The PROGRESSOR offers a single visual display which adds change in visual field sensitivity over a period of time to the conventional information about size and density of scotoma. The size of the printed bars at each location indicates the density of the scotoma and there is a contiguous bar for each time the test has been performed. Each location plot is therefore a miniature histogram and the colour of the bars shows the probability of any change in density of scotoma being significant. There is a range of colours based on the convention red for dangerdeterioration, green for safety-improvement. White is used for the highest probability of significant progressive loss and we might regard this as representing 'white hot'. Further refinement may yet be required to address further questions. Is it possible to standardise and display the timescale of the tests and will observers with defective colour vision read the results accurately?

In addition, will it be possible to incorporate information so that change in field sensitivity might be compared with the average expected rate of visual field decay in eyes which are well treated. This often covers an interval of up to 40 years ${ }^{12}$ and a slope close to this optimum will be more than adequate to maintain vision during the life of the patient. Indeed, a significant part of this slow deterioration in treated cases may be caused not by progressive disease but by the gradual reduction in the numbers of optic nerve axons with increasing age. At birth there are between 1.0 million and 1.5 million and several studies indicate the loss of about 5000 per annum throughout life. ${ }^{3-7}$ Individual variation is considerable ${ }^{8}$ but, assuming a complement of axons at 60 years of age of 700000 and a possible loss of up to $40 \%$ during a period of ocular hypertension before field defects are detectable by standard tests, ${ }^{9}{ }^{10}$ it may be that a 60 year old patient with primary open angle glaucoma in whom field changes are just starting to appear has 420000 axons. If the subsequent decay of these axons can be extended over 40 years, which is the estimated survival of visual field on optimum treatment, the rate of axon loss will be about 10000 per annum; thus for well treated glaucoma the average rate of optic nerve deterioration might be only twice that of normal aging. Shall we soon have the opportunity to display the progress of our patients against the normal decay for age and optimum treated disease?

In busy glaucoma clinics there is a need for a test which can be interpreted rapidly and this facility may be more important than increased sensitivity for detection of minor changes. Few treated glaucoma patients show change in visual field over many years, whether tested by manual kinetic or automated methods. ${ }^{112}$ Yet new methods are continually proposed to increase the sensitivity of field tests; spatial processing and logistic discriminant analysis are but two recent examples. ${ }^{13}{ }^{14}$ There is therefore a danger that research and innovation in visual field tests for glaucoma are being driven by the supplier rather than the consumer, either patient or clinician. ${ }^{15}$

The chase for ever increasing test sensitivity is inappropriate for the management of most patients and may divert research interest from neglected areas such as the pathophysiology of intraocular pressure control and long term study of the progress of untreated disease and how it is influenced by treatment. Meanwhile the goal of incorporating all the required information for visual field interpretation on one pictorial display is worth pursuit.

JEFFREY L JAY

Tennent Institute of Ophthalmology, University of Glasgow, Glasgow G11 6NT

1 Smith RJH. The enigma of primary open angle glaucoma. Trans Ophthalmol Soc UK 1986;105:618-33.

2 Jay JL. Rational choice of therapy in primary open angle glaucoma. Eye 1992;6:243-7.

3 Balazsi AG, Rootman J, Drance SM, Douglas GR. The effect of age on the nerve fibre population of the human optic nerve. Am f Ophthalmol 1984;97:760-6.

4 Johnson BM, Miao M, Sadun AA. Age related decline of human optic nerve axon population. Age 1987;10:5-9.

5 Mikelberg FS, Drance SM, Schulzer M, Yidegiligne HM, Weiss MM. The normal human optic nerve. Ophthalmology 1989;96:1325-8.

6 Jonas JB, Muller-Bergh JA, Schlotzer-Schrehardt UM, Naumann GOH. Histomorphometry of the human optic nerve. Invest Ophthalmol Vis Sci 1990;31:736-44

7 Morrison JC, Cork LC, Dunkelberger GR, Brown A, Quigley HA. Ageing changes of the rhesus monkey optic nerve. Invest Ophthalmol Vis Sci 1990; 31:1623-7.

8 Jonas JB, Schmidt AM, Muller-Bergh JA, Schlotzer-Schrehardt UM, Naumann GOH. Human optic nerve fibre count and optic disc size. Invest Ophthalmol Vis Sci 1191;30:2012-8.

9 Quigley HA, Addicks EM, Green WR. Optic nerve damage in human glaucoma. III Quantitative correlation of nerve fibre loss and visual field defect in glaucoma, ischaemic optic neuropathy, papilloedema and toxic in glaucoma, ischaemic optic neuropathy,

10 Quigley HA, Dunkelberger GR, Green WR. Studies of retinal ganglion cell atrophy correlated with automated perimetry in human eyes with glaucoma. Am f Ophthalmol 1989;107:453-64.

11 Smith SD, Katz J, Quigley HA. Analysis of progressive change in automated visual field in glaucoma. Invest Ophthalmal Vis Sci 1996;37:1419-28.

12 Katz J, Gilbert D, Quigley HA, Sommer A. Estimating progression of visual field loss in glaucoma. Ophthalmology 1997;104:1017-25.

13 Anton A, Moquet JA, Mayo A, Tapia J, Pastor JC. Value of logistic discriminant analysis for interpreting initial visual field defects. Ophthalmology 1997;104:525-31.

14 Crabb DP, Fitzke FW, McNaught AI, Edgar DF, Hitchings RA. Improving the prediction of visual field progression in glaucoma using spatial processing. Ophthalmology 1997;104:517-24.

15 Liberati A. Consumer participation in research and health care. BMf 1997; 315:499. 